\title{
Wind Turbines: Why Some Families Living in Proximity to Wind Energy Facilities Contemplate Vacating Their Homes: An Overview of Findings
}

\author{
Carmen M. Krogh ${ }^{1}$, Robert Y. McMurtry², W. Ben Johnson ${ }^{3}$, Anne Dumbrille ${ }^{4}$, \\ Mariana Alves-Pereira' ${ }^{5}$, Jerry L. Punch ${ }^{6}$, Debra Hughes ${ }^{7}$, Linda Rogers ${ }^{8}$, \\ Robert W. Rand ${ }^{9}$, Richard James ${ }^{10}$, Stephen E. Ambrose ${ }^{11}$, Lorrie Gillis ${ }^{12}$ \\ ${ }^{1}$ Magentica Research Group, Member of the Board of Directors, Canada \\ ${ }^{2}$ School of Medicine and Dentistry, Western University, London, Ontario, Canada \\ ${ }^{3}$ The Iowa Heart Center, Des Moines, Iowa, USA \\ ${ }^{4}$ CCSAGE Naturally Green (County Coalition for Safe and Appropriate Green Energy), Chair, Picton, Ontario, Canada \\ ${ }^{5}$ School of Sciences for Economics and Organizations, Lusofona University, Lisbon, Portugal \\ ${ }^{6}$ Department of Communicative Sciences and Disorders, Michigan State University, Michigan, USA \\ ${ }^{7}$ Independent, West Lincoln, Canada \\ ${ }^{8}$ Mothers against Wind Turbines, Member of the Board of Directors, Haldimand, Canada \\ ${ }^{9}$ Acoustical Society of America (ASA), Institute of Noise Control Engineering (INCE) Member Emeritus, Brunswick, USA \\ ${ }^{10}$ Acoustical Society of America (ASA), Institute of Noise Control Engineering (INCE) through 2017, Okomos, USA \\ ${ }^{11}$ Institute of Noise Control Engineering (INCE) Emeritus, Acoustical Society of America (ASA) Emeritus, Windham, USA \\ ${ }^{12}$ Independent, Grey Highlands, Canada \\ Email: *carmen.krogh@gmail.com
}

How to cite this paper: Krogh, C.M., McMurtry, R.Y., Johnson, W.B., Dumbrille, A., Alves-Pereira, M., Punch, J.L., Hughes, D., Rogers, L., Rand, R.W., James, R., Ambrose, S.E. and Gillis, L. (2020) Wind Turbines: Why Some Families Living in Proximity to Wind Energy Facilities Contemplate Vacating Their Homes: An Overview of Findings. Open Access Library Journal, 7: e6443. https://doi.org/10.4236/oalib.1106443

Received: May 18, 2020

Accepted: June 25, 2020

Published: June 28, 2020

\begin{abstract}
Background: Some families living near wind energy facilities report permanently vacating their homes while others contemplate doing so. While these events are reported on the Internet and social media, research is lacking. This study explored why some people living in proximity to wind turbines contemplate such housing decisions. Methods: This ethics-reviewed study used the Grounded Theory methodology and audio recorded interviews with those who had previously lived, or were currently living near wind turbines. Audio files were transcribed to text, and the data analysed using NVivo12 Pro software. Objectives: To explore the events that influenced families living within $10 \mathrm{~km}$ from wind energy facilities to contemplate vacating their homes. To generate a substantive theory regarding these housing decisions. Results: All 67 participants associated occurrences of adverse health effects, or the potential for such effects when living within $10 \mathrm{~km}$ of a wind energy facility. Some temporarily left during the day and/or night to alleviate effects. Discussion: This article presents an overview of results with additional details pending in future peer-reviewed
\end{abstract}


Copyright $\odot 2020$ by author(s) and Open Access Library Inc.

This work is licensed under the Creative Commons Attribution International License (CC BY 4.0).

http://creativecommons.org/licenses/by/4.0/ articles. Using a systematic methodology, data analysis lends support for the theory that housing decisions were motivated by the proximity of wind energy facilities within $10 \mathrm{~km}$ of homes and the interviewees' observations of the occurrence or potential risk of adverse health effects. Members of the public, researchers, health care practitioners, engineers and acousticians, social scientists, and policy makers with an interest in health and social policy are presented with the potential outcomes of placing wind turbines near family homes.

\section{Subject Areas}

Civil Engineering, Sociology

\section{Keywords}

Wind Turbines, Wind Energy Facilities, Chronic Noise, Vacated and Abandoned Homes, Adverse Health Effects, Grounded Theory, Personal Interviews

\section{Introduction}

Typically, reasons associated with housing decisions include: seeking a better home or apartment or a less expensive living situation; achieving home ownership or relocating to a better neighbourhood; establishing a household or a change in marital status; an employment opportunity; retirement; down-sizing; health factors; wanting a change of climate or escaping from a natural disaster [1] [2]. While reports of people contemplating housing decisions associated with living near wind turbines are available through peer-reviewed literature [3], testimony [4] [5], talks [6] [7] [8], social media [9], news reports [10] and investigative reporting [11], research regarding the decision-making process and the extent and outcomes of these occurrences is lacking.

Internationally and prior to this study being conducted, some families had reported adverse health events [3] [4] [5] [12]. In some cases, Canadian families have abandoned their homes [4] [13], "been billeted by wind energy developers, or negotiated financial agreements with developers" [13].

While the risk for harm to humans associated with exposure to a wind energy facility is controversial and debated globally [11] [13]-[18], a major conclusion of an impact study found that "People living in the vicinity of wind turbines are at risk of being annoyed by the noise, an adverse effect in itself" and that noise annoyance could lead to "sleep disturbance and psychological distress" [19]. An assessment of European residential noise exposure concluded that the result "confirms the thesis that for chronically strong annoyance a causal chain exists between the three steps health—strong annoyance-increased morbidity" [20] and that "with regard to criteria for causal relations-confirmed on an epidemiological level, an increased health risk from chronic noise annoyance" [21] and it had to be assumed that chronic noise annoyance connected with risks for arthritis, migraine, cardiovascular and respiratory symptoms such as bronchitis [21]. Further- 
more, research indicates that chronic stress has been linked to the development of insulin resistance, a risk factor for "non-insulin-dependent diabetes" and that:

Stressful experiences include major life events, trauma, and abuse and are sometimes related to the environment in the home, workplace or neighborhood. Acute stress (in the sense of "fight or flight" or major life events) and chronic stress ...can both have long-term consequences." [22].

The purpose of this study was to explore the events that influenced individuals and families living within $10 \mathrm{~km}$ of an industrial wind turbine (IWT) facility to contemplate whether to permanently vacate/abandon their homes. A Qualitative research methodology, specifically the Grounded Theory (GT) proposed by Castillo-Montoya (2016) [23], was employed to conduct this study.

The Grounded Theory methodology is an iterative process where sampling and data collection continues until theoretic saturation is achieved [24]. Theoretic saturation occurs until "no new insights or new dimensions to categories" are being identified [25]. In this study, theoretic saturation was reached with the $67^{\text {th }}$ interview, at which point the invitation to participate was closed.

Data analyses of the sentiments and observations described by study participants revealed a compilation of themes and sub-themes. Due to the volume of data acquired, future peer-reviewed articles will explore and elaborate on the themes and sub-themes described in Figure 1.

Element 5: The aftermath of actions and interactions

- Displacement, anger, loss of confidence in government

- Financial hardship

- Effects on relationships
Element 1: The central phenomenon/ event

- Industrial wind turbine facilities within $10 \mathrm{~km}$ of family homes

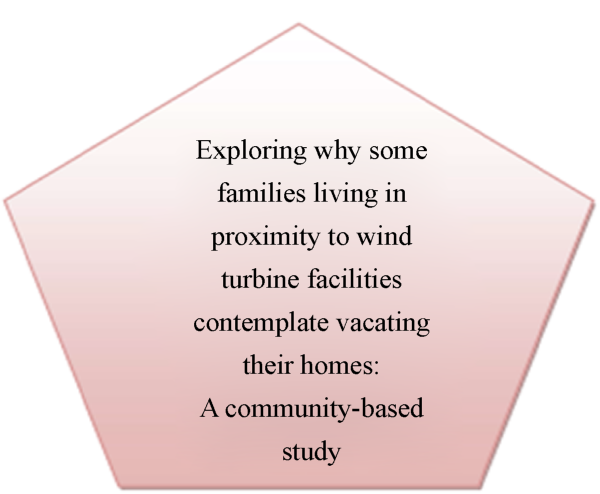

Element 2: The causal conditions environmental interference and altered living conditions

- Physical, psychological and social well-being

- Electrical fields

- Wind turbine noise, vibration, atmospherics and wind conditions

- Pets and animals

- Well water disruption

- Personal viewpoints, social justice, safety and security
Element 4: The actions and interactions taken: response to living within $10 \mathrm{~km}$ of wind turbines

- Vacated/abandoned a home (permanently)

- Contemplating to vacate/abandon

- Temporarily/intermittently vacated

- Pre-emptively vacated

- Intending to remain
Element 3: The context in which the phenomenon/event is embedded: becoming informed and taking action

- Green Energy Act 2009

- Communicating with authorities and others

- Filing Incident Reports/Complaints

- Observed and/or participated in judicial proceedings

Figure 1. Themes and sub-themes and their relationship to the 5 Elements. 


\section{Methods}

\subsection{Synopsis of Methods}

Krogh et al. (2020) [26] provide a synopsis of the ethics approval process, general methodology and research questions of this study.

\subsection{Inclusion and Exclusion Criteria}

Potential participants were advised their home must be within $10 \mathrm{~km}$ of a wind energy facility and that they have permanently vacated/abandoned their home or be currently contemplating to do so.

Partaking in the study was voluntary and participants were not paid. Those who wished to participate could do so as a family group or through a family member delegated to represent the family. Participants and the individual representing the family had to be 18 years or older, fluent in the English language and must not have any cognitive impairment.

\subsection{Invitation to Participate}

The invitation stated that the study would give participants an opportunity to describe the circumstances that may influence individuals and families "whether to vacate or remain in their home" and to explore the "extent of these occurrences and the impact or lack of impact" of living within $10 \mathrm{~km}$ of a wind energy facility. It summarized the study's purpose, the personal (face-to-face) interview, inclusion/exclusion criteria and other details.

There were no restrictions to the invitation's distribution. All eligible participants, including those who had entered into a lease agreement with a wind developer were eligible to participate. However, no one with such a lease did so. Invitations were distributed to community group leaders and to individuals who were known to have permanently vacated their homes or were contemplating to do so. Awareness of the study was expected to occur through word of mouth, the Internet and social media. Those interested in participating were invited to contact Principal Investigator Krogh to obtain more details.

\subsection{Interviews, Consent and Data Collection}

Trained interviewers conducted the interviews between October 2017 and January 2018. Process requirements such as logistics, scheduling and records including data control by the study Scrutinizer, were facilitated and managed by the Process Controller. Prior to the interview, participants were invited to ask questions about the study and consent form. Those interviewed were advised that any information collected on the family would be protected including locked storage with access limited to the research analytical team. Prior to signing the consent form, participants were advised that the intention was to publish results in peer-reviewed journals and personal identity and anonymity would be protected. Editors, peer-reviewers, and those reading the articles would not have access to participants' personal information. Participants were also advised that at any time, 
even if they had signed the consent form, they could decline to answer any question and could change their mind and withdraw from participating. If the family withdrew, all data collected on the family would be immediately destroyed. None of the participants withdrew their consent or the information that was collected from the study. The interviewer and each participant, including paired participants ( 2 participants interviewed together) signed a consent form that was retained by these individuals.

A brief questionnaire collected background and demographic data that were validated and compiled into Microsoft Office Excel by the study's Scrutinizer and Process Controller. All 67 participants consented to audio recording the interview and were offered a DVD copy at its conclusion. The audio files were transcribed to text files by a transcription service (https://gotranscript.com/). Coding and data analysis were conducted using NVivo12 Pro software

(http://www.qsrinternational.com).

\subsection{Data Security, Integrity and Storage}

A strict protocol was and continues to be employed to protect confidentiality and integrity of study records. Data are stored in a secure and locked location with access limited to the research analytical team. All data and records will be secured in locked storage for five years and then destroyed.

\subsection{Confirmation of Data Coding}

The iterative process captured the comments and descriptions of study participants. These were coded and data analyses determined the themes and sub-themes as described in Section 3.3 Themes and sub-themes. Four colleagues were provided with excerpts related to these themes and sub-themes and independently reviewed and confirmed the data analyses. Those conducting this review were not provided with the personal identification of participants.

\section{An Overview of Results}

\subsection{Demographic Distribution}

Table 1 presents a breakdown of the research participants' statistical and demographic information.

Participants in this study (N-67) included 42 females (62.7\%) and 25 males (37.3\%). Nineteen couples participated. The mean age was $61.4 \pm 10.6$ years. The age range for females was 41.9 - 82.3, with a mean age of $60.9 \pm 9.7$; the range for males was $30.8-81.7$ with a mean of $62.3 \pm 12.2$ respectively. Seventy-six percent of the participants completed post-secondary education. Their occupational fields represented all 10 of the StatsCan categories. The most frequent were Trades, Transport, Equipment Operators (20.9\%), followed by Education, Law, Social, Government (16.4\%). The mean length of time participants had lived in their rural residence located within $10 \mathrm{~km}$ of a wind turbine was 20.7 years \pm 14.6 years with a range of 3 - 66 years. 
Table 1. Statistical and demographic information.

\begin{tabular}{|c|c|c|c|c|c|}
\hline \multicolumn{6}{|c|}{ Descriptive Statistics } \\
\hline & $\mathrm{N}$ & Minimum & Maximum & Mean & SD \\
\hline Age at Interview in Years & 67 & 30.8 & 82.3 & 61.44 & 10.64 \\
\hline \multirow[t]{2}{*}{ \# years at this location (2018) } & 67 & 3 & 66 & 20.69 & 14.58 \\
\hline & & & Frequency & \multicolumn{2}{|c|}{ Percent } \\
\hline \multirow[t]{2}{*}{ Gender } & \multicolumn{2}{|c|}{ Male } & 25 & \multicolumn{2}{|c|}{37.3} \\
\hline & \multicolumn{2}{|c|}{ Female } & 42 & \multicolumn{2}{|c|}{62.7} \\
\hline \multirow[t]{3}{*}{ Education } & \multicolumn{2}{|c|}{ High School diploma } & 14 & \multicolumn{2}{|c|}{20.9} \\
\hline & \multicolumn{2}{|c|}{ Trade diploma } & 2 & \multicolumn{2}{|c|}{3} \\
\hline & \multicolumn{2}{|c|}{ College or University } & 51 & \multicolumn{2}{|c|}{76.1} \\
\hline \multirow[t]{10}{*}{ Occupational Sector } & \multicolumn{2}{|c|}{ Homemaker } & 1 & \multicolumn{2}{|c|}{1.5} \\
\hline & \multicolumn{2}{|c|}{ Management } & 8 & \multicolumn{2}{|c|}{11.9} \\
\hline & \multicolumn{2}{|c|}{ Business, finance, admin } & 9 & \multicolumn{2}{|c|}{13.4} \\
\hline & \multicolumn{2}{|c|}{ Health } & 9 & \multicolumn{2}{|c|}{13.4} \\
\hline & \multicolumn{2}{|c|}{ Education, law, social, govt } & 11 & \multicolumn{2}{|c|}{16.4} \\
\hline & \multicolumn{2}{|c|}{ Arts, culture, rec \& sport } & 1 & \multicolumn{2}{|c|}{1.5} \\
\hline & \multicolumn{2}{|c|}{ Sales \& service } & 2 & \multicolumn{2}{|c|}{3} \\
\hline & \multicolumn{2}{|c|}{ Trades, transport, eqpt operators } & 14 & \multicolumn{2}{|c|}{20.9} \\
\hline & \multicolumn{2}{|c|}{ Natural resources, agriculture } & 9 & \multicolumn{2}{|c|}{13.4} \\
\hline & \multicolumn{2}{|c|}{ Manufacturing, utilities } & 3 & \multicolumn{2}{|c|}{4.5} \\
\hline
\end{tabular}

\subsection{Home Status of Participants}

Figure 2 illustrates the home status of the 67 participants at the time of the interviews.

Home Status at Time of Interview

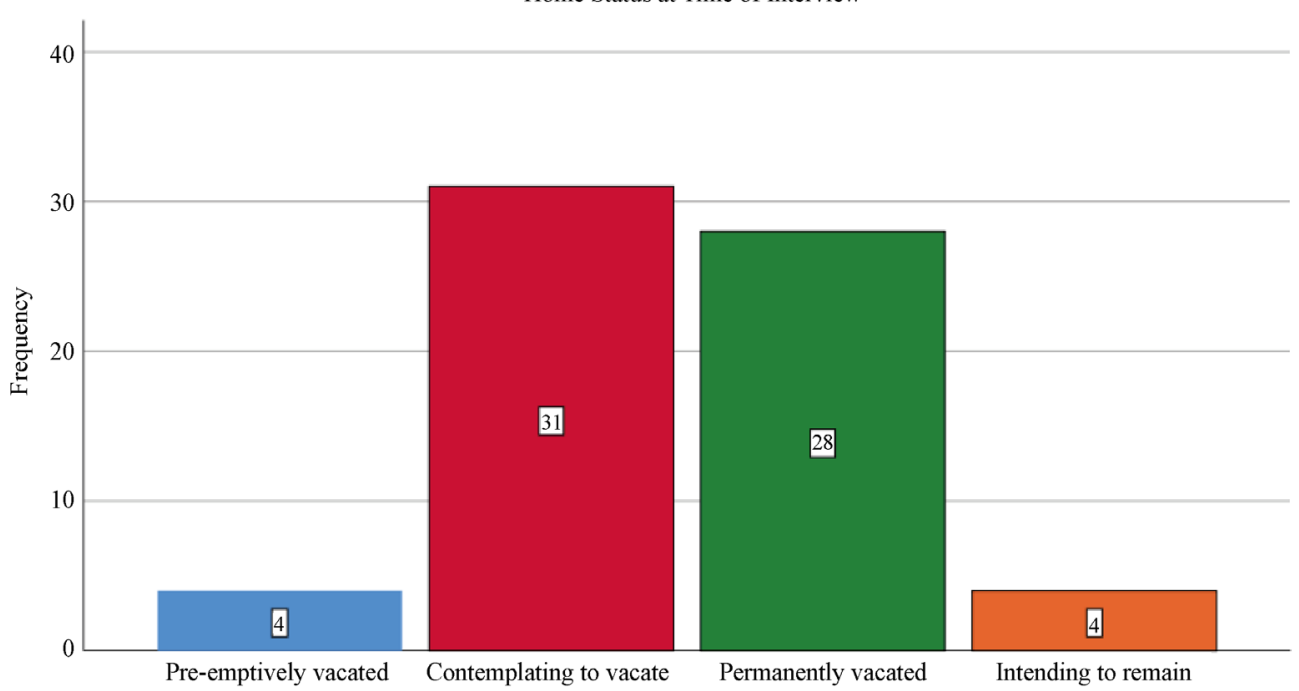

Figure 2. Home status at time of interviews. 
Of the 67 interviewees, 28 had permanently vacated/abandoned their home; 31 were contemplating to do so; 4 pre-emptively left prior to the wind energy facility initiating operations; and 4 intended to remain in their homes. Regarding the latter category, 2 intended to remain in their home unless adverse effects occurred; and the other 2 expressed a preference to live in a rural environment.

Figure 3 presents findings relating to participants temporarily/intermittently vacating their homes.

Prior to permanently vacating their homes, 24 of the 28 study participants temporarily and intermittently left their homes during the day and/or night to alleviate adverse health effects. At the time of the interviews, 12 of the 31 participants contemplating to permanently vacate their homes were also temporarily and intermittently leaving during the day and/or night for similar reasons. Overall, of the 67 interviewees, a total of 36 reported taking these steps in order to obtain temporary and/or partial relief from the occurrence of adverse health effects.

\subsection{Themes and Sub-Themes}

The Grounded Theory iterative process identified numerous themes and sub-themes that evolved as the interviews progressed.

Figure 1 presents a schematic view of the themes and sub-themes derived from data analyses and their relationship to the 5 elements. The 5 elements are described in Table 2.

Table 2 illustrates the 5 elements proposed by Rose et al. (2015) and its application to the vacated home study [25].

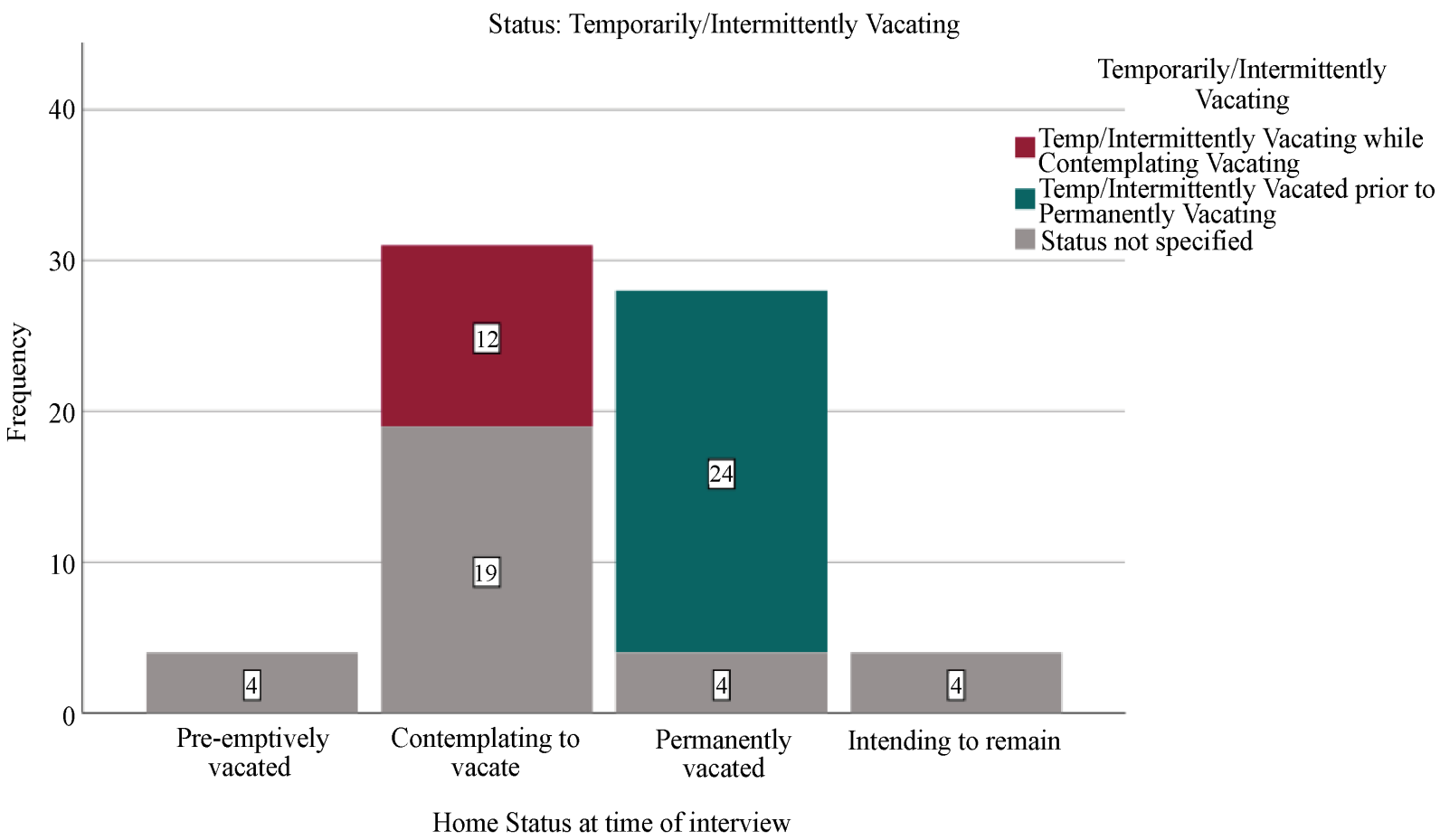

Figure 3. Temporarily/intermittently vacating during the day and/or night. 
Table 2. Five elements and its application to the vacated/abandoned home study $[26]^{*}$.

\begin{tabular}{|c|c|}
\hline Proposed by Rose et al., 2015 [25] & $\begin{array}{l}\text { Why some families living in proximity to wind turbine } \\
\text { facilities contemplate vacating their homes }\end{array}$ \\
\hline Element 1 & Element 1 \\
\hline \multirow[t]{2}{*}{$\begin{array}{l}\text { The central phenomenon that is the } \\
\text { focus of the study. }\end{array}$} & $\begin{array}{l}\text { The central phenomenon/event is the siting of an industrial } \\
\text { wind energy facility within } 10 \mathrm{~km} \text { of family homes. }\end{array}$ \\
\hline & Element 2 \\
\hline \multirow[t]{2}{*}{$\begin{array}{l}\text { The causal conditions that contribute } \\
\text { to the phenomenon. }\end{array}$} & $\begin{array}{l}\text { The causal conditions are described in the themes and } \\
\text { sub-themes such as environmental interference, altered } \\
\text { perceptions and living conditions that participants associated } \\
\text { with an operational industrial wind energy facility within } 10 \\
\text { km of their family home. }\end{array}$ \\
\hline & Element 3 \\
\hline $\begin{array}{l}\text { The context in which the phenomenon } \\
\text { is embedded. }\end{array}$ & $\begin{array}{l}\text { The context is embedded in a government policy with } \\
\text { research participants becoming informed and taking action } \\
\text { through various processes such as filing complaints and } \\
\text { participating in legal/judicial processes. }\end{array}$ \\
\hline \multirow{4}{*}{$\begin{array}{l}\text { The actions and interactions taken by } \\
\text { people in response to the } \\
\text { phenomenon. }\end{array}$} & Element 4 \\
\hline & \\
\hline & $\begin{array}{l}\text { The actions and interactions taken resulted in } \\
\text { participants contemplating housing decisions such as: } \\
\text { vacating/abandoning a family home; contemplating to do so; } \\
\text { pre-emptively vacating; periodically and intermittently } \\
\text { vacating; or deciding to remain. }\end{array}$ \\
\hline & Element 5 \\
\hline $\begin{array}{l}\text { The consequences of those actions and } \\
\text { interactions. }\end{array}$ & $\begin{array}{l}\text { The consequences of these actions and interactions taken in } \\
\text { Element } 4 \text { include participants' sentiments and expressions } \\
\text { of an "aftermath" such as: profound losses; effects related to } \\
\text { social justice, rights, personal security; grief, displacement, } \\
\text { anger, bitterness, mistrust, stress and anxiety; financial losses } \\
\text { and hardship and impact on employment; and effects on } \\
\text { relationships. }\end{array}$ \\
\hline
\end{tabular}

${ }^{*}$ Originally published in the Open Access Library Journal: Krogh, C.M., McMurtry, R.Y., Dumbrille, A., Hughes, D. and Gillis, L. (2020) Preliminary Results: Exploring Why Some Families Living in Proximity to Wind Turbine Facilities Contemplate Vacating Their Homes-A Community-Based Study. Open Access Library Journal, 7: e6118. https://doi.org/10.4236/oalib.1106118.

\section{Element 1: The Central Phenomenon/Event Is the Siting of an Industrial Wind Energy Facility within $10 \mathrm{~km}$ of Family Homes}

To initiate the discussion, the opening question was framed as neutrally as possible: "Can you discuss the events that led you to decide to vacate your home or think about vacating your home?"

Data analysis reveals that in response to the opening question, all of the 67 participants identified the central phenomenon/event was an operating or pending wind turbine project in proximity to their homes. 
At the same time, as depicted below in section 5.0 Element 2: The causal conditions - themes and sub-themes, all of the 67 participants associated the proximity of an industrial wind energy facility with the occurrence of adverse health effects, or the potential of this taking place.

The preliminary findings indicate that while 67 people were interviewed, 98 additional members were living in these homes for a total of 165 individuals. Some of the participants expressed concerns that others such as children, grandchildren, relatives, visitors and guests had described a variety of adverse health effects (AHE) that were consistent with the effects being described by some of the participants [26]. These concerns will be considered in future articles.

Examples of the sentiments expressed by participants are provided throughout this overview. Due to the volume of data acquired, examples are limited until the themes and sub-themes are explored in future articles. The acronyms for the home status of participants are:

[V] Permanently Vacated/Abandoned

[V-T/I] Vacated/Abandoned (Permanently)-Temporarily/intermittently*

[CV] Contemplating to Vacate/Abandon

[CV-T/I] Contemplating to Vacate/Abandon-Temporarily/intermittently ${ }^{* *}$

[P-EV] Pre-emptively Vacated/Abandoned prior to turbines initiating operations

[R] Remaining

${ }^{*}$ prior to permanently vacating their homes participants temporarily/intermittently left their homes during the day and/or night.

${ }^{* *}$ while contemplating their housing options, participants temporarily/intermittently left during the day and/or night.

Examples:

The turbines affected me from the first day that they were spinning. I became sick right away [V].

Wind turbines do affect us... I have ringing in my ears and [problems] sleeping... I'm exhausted... The impact has gotten worse and worse [CV].

... we became involved in the issues with turbines... the first real concern was the health issues... because we both have health issues [P-EV].

... we never pursued wind turbines for ourselves ... I'm concerned about my health $[R]$.

\section{Element 2: The Causal Conditions-Themes and Sub-Themes}

Element 2 indicates the causal conditions that were described by interviewees. Data analyses revealed instances of environmental interference and altered living conditions and sub-themes that participants associated with an operational a wind energy facility.

Sub-themes are:

- Physical, psychological and social well-being

- Electrical fields 
- Wind turbine noise, vibration, atmospherics and wind conditions

- Pets and animals

- Well water disruption

- Personal viewpoints, social justice, safety and security

\subsection{Physical, Psychological and Social Well-Being}

Examples:

I couldn't sleep anymore... there was never any remedy to get away from the noise [V].

I'm alone now. My husband had passed away... it's becoming more apparent... that I need to leave here if I want to survive [CV].

$\ldots$ it caused us a lot of stress and a lot of hard decisions [P-EV].

I have concerns so that they [majority of people] will always think that this has to do with the greater good ... that people have to suffer for the greater $\operatorname{good}[\mathrm{R}]$.

\subsection{Electrical Fields}

Examples:

... when the project started up, not only did we feel it... measurements found that there were significant amounts of electrical pollution coming into the house $[\mathrm{V}]$.

... we had hydro come... Probably four or five times... they pointed over there [to the turbine] and said "There's where your problem is." [CV].

\subsection{Wind Turbine Noise, Vibration, Atmospherics and Wind Conditions}

Examples:

... the noise varied, one time when the Ministry official was here he said "I can't hear the vibration because of the noise of the blades." [V].

... the noise bounces off the steel sheds and bounces back towards me at the house. ... [there's] no safe-house, nowhere to go, there's no hiding from it $[\mathrm{CV}]$.

\subsection{Pets and Animals}

Examples:

... very rarely was the house not vibrating... we were feeling it... [behavioural changes indicated] our pets were feeling it... the animals were hurting [V].

She's a German shepherd... I'm assuming it's vertigo because her head will sway and she'll throw up... when he [developer] was here, he saw her with vertigo too $[\mathrm{CV}]$. 


\subsection{Well Water Disruption}

Examples:

We had beautiful hard water... You couldn't drink the water afterwards [after turbines started operating] [V].

... my well water is disturbed. I have gray water in my toilet bowl all the time. I can change the filters, but it's there again [CV].

[wind turbine developers] swore on a stack of Bibles that their construction and their operation would not impact the local water wells... after they started construction, there have been as far as I know to this day, 13 wells impacted $[\mathrm{R}]$.

\subsection{Personal Viewpoints, Social Justice, Safety and Security}

\section{Examples:}

I was in favor of wind power until these [health] issues occurred [V].

I was very supportive of renewable energy options... [now] there's a big "but" there [CV].

... with the effects of the wind turbine, I felt dizzy and lightheaded. I was on crutches and I didn't feel safe [V].

[wind turbines] got approved... It doesn't feel quite safe anymore [CV].

In a rural community, there's almost no place that's guaranteed to be safe $[R]$.

\section{Element 3: Becoming Informed and Taking Action}

The context is embedded in a government initiative-Ontario's Green Energy and Economy Act of 2009 [27]. Participants described becoming informed and taking action such as communicating with wind developers, elected and other officials, filing complaints/Incident Reports and attending, supporting and/or taking part in judicial proceedings. Sub-themes are:

- Green Energy Act 2009

- Communicating with authorities and others

- Filing Incident Reports/Complaints

- Observed and/or participated in judicial proceedings

\subsection{Green Energy Act 2009}

Examples:

Then the Green Energy Act consultation came up... I'd been denied a place to speak. I was shocked... I was beginning to realize how bad it was [V]. I felt as though the Green Energy Act... in our case is like the War Measures Act. Our rights have been ripped from us. It's so clever how it blocks every avenue... [CV].

... the turbines were going to be put in... [because of] the Green Energy Act [P-EV].

It looks like they [Ministry of Environment] are deliberately trying to avoid any regulations that would hamper a wind development [R]. 


\subsection{Communicating with Authorities and Others}

Examples:

... we talked to Health Canada... our [local Member of Parliament], ... our

[local Member of Provincial Parliament]... our town Council... I don't know that there was anybody we didn't talk to [V].

The medical health officer believes us and she says there's nothing she can do about it [V].

[I asked] my family doctor... "Is it a possibility about turbines?" And she said, "Yes." [CV].

[I communicated with]... the health unit... Prime Minster [Canada]... Premier [Ontario]... MOECC [Ministry of Environment and Climate Change]... energy [Minister of Energy] ... councillors... nurse practitioner... other community members... people who I met off the street... people's relatives, people that might be coworkers, other professionals, the ear/nose/throat specialist... township, ... [ wind energy] companies responsible [CV].

I went to a lot of open houses... [talked to] our local mayor... our councillor... I don't know how many letters I [ wrote]... We did what we could [R].

\subsection{Filing Incident Reports/Complaints}

Examples:

They may have a protocol for taking down the complaints but nothing to deal with them [V].

I have written a lot of letters of complaint... Premier Wynne [former Premier of Ontario] said there had only been a handful of complaints ... many thousands of our reports had just been dismissed [CV].

There're unanswered complaints everywhere $[R]$.

\subsection{Observed and/or Participated in Judicial Proceedings}

Examples:

When I testified at the Environmental Review Tribunal, [my physician] wrote a letter of support for me... His conclusion of the medical diagnostic [information] was he couldn't see any other reason than exposure to a noise source such as I suspected was causing my issues. They [the Tribunal found no cause for my issues [V].

... families who had appealed [wind turbine] project-what they went through-just to watch them go through that every day was painful. If you have any empathy for people-what they had to face [CV].

The test is impossible... unfair is the word... the onus of proof being on the individual to prove harm... that is extremely unique in this environment. It's just unfathomable that somebody would have to prove harm... It was very odd having our government in there against us instead of protecting us [R]. 


\section{Element 4: Housing Decisions}

The actions and interactions taken resulted in participants contemplating housing decisions.

Examples:

Eventually we just didn't stay at that house-we rented permanently away from the home... until we were permanently not at the home [V].

I went to [location] for a month to get away from the turbines. I rented a cottage-I lived at the cottage for two months... I stayed at the trailer for two more months [V-T/I].

We've built a cabin on our property that we're able to sleep in... [but] now that we're back in the house... We go away whenever we have an opportunity $[\mathrm{CV}-\mathrm{TI}]$.

... you have to be away from home for more than just a night... I've been sleeping at my daughter's... for the last three weeks. You have to be away from it [longer] than just 10 hours or 11 hours [CV-T/I].

\section{Element 5: An Aftermath}

As shown in Element 4, participants described an aftermath related to the consequences of the actions and interactions of their housing decisions. These will be discussed in future peer-reviewed articles. The sub-themes are sentiments and expressions of:

- Displacement, anger, loss of confidence in government

- Financial hardship

- Effects on relationships

\subsection{Displacement, Anger, Loss of Confidence in Government} Examples:

... it was basically like a death when we had to move from home... nothing was familiar, nothing seemed like it was ours... it was just a second death [V]. I think that I get bitter... I feel like my whole personality has changed where I've become mean and bitter... you feel like you've been betrayed by people... [CV].

That was a real eye-opener about how the government manipulates and they don't care [P-EV].

[It $s$ ] extremely aggravating when our own provincial government is acting on behalf of out of province and out of country developers in many cases to the detriment of the residents [R].

\subsection{Financial Hardship}

Examples:

We had a plan for our retirement... my working and that was our retirement... I was forced to leave my career... It's been an emotional... a physical... 
a financial disaster [V].

I started to look at a [Real Estate] listing... it was money out of our pocket that we did not have... [CV].

... the decision to sell because of the turbines basically put us unemployed. Basically knowing the health issues... [P-EV].

\subsection{Effects on Relationships}

Examples:

... it was sad. it was disheartening, disappointing, the lack of response by people you thought would be there to help you... Just at a human level-to care $[\mathrm{V}]$.

... it causes some marital problems [CV].

As a Christian, we can't stand by and let harm happen to our neighbors... church politics is a lot like politics at large... we ended up getting excommunicated saying that we slandered our church members by saying "They [turbines] were harming their neighbors." $[I t]$ put a lot of strife in our family situation ... we got a letter from [a relative] saying "Since we are excommunicated and no longer considered Christian, we are no longer welcome at family gatherings." The churches are failing. That's another aspect of the family conflict [P-EV].

... to get the majority of people to understand and to relate to them [wind turbines].., I think it's going to take time [R].

\section{Conclusions}

This study applied the Grounded Theory methodology to explore the events that motivated families living within $10 \mathrm{~km}$ from a wind energy facility to contemplate vacating/abandoning their homes.

Data analyses revealed a number of themes and sub-themes. Due to the extent of findings, this article is limited to an overview of results with additional details to be provided in future peer-reviewed articles.

There are numerous reasons associated with housing decisions. See section 1.0 Background, In this study, all of the 67 participants indicated that a wind energy project within $10 \mathrm{~km}$ of their homes and the occurrence of adverse health effects or a risk of this potentially happening were the factors associated with their housing decisions.

Using a systematic methodology, data analysis lends support for the theory that housing decisions were motivated by the proximity of a wind energy facility within $10 \mathrm{~km}$ of homes and the participants' observations of the occurrence or potential risk of adverse health effects.

Members of the public, researchers, health care practitioners, engineers and acousticians, social scientists, and policy makers with an interest in health and social policy are presented with the potential outcomes of placing wind turbines near family homes. 


\section{Acknowledgements}

This article is dedicated to those who participated in this important research and described their experiences when living in proximity to industrial wind energy facilities. They welcomed our interviewers into their homes and spoke openly about the impact on their lives and that of their families after permanently vacating their family homes and while contemplating to do so. Our research team and the authors of this article respect the opportunity to bring these findings forward. We acknowledge the interviewers who volunteered their time and travelled substantive distances to conduct the interviews; our Scrutinizer who examined and compiled the demographic data; and those who volunteered to review and confirm the data analysis, coding procedures and the derived themes and sub-themes. Finally, we thank those who encouraged us to conduct the study and who provided the funding for the Ethics Review, the coding software and costs associated with Open Access publishing which enabled the conduct of this study and its publication.

\section{Funding}

MAGENTICA RESEARCH GROUP. Not for Profit (Corporations Canada). Partially funded by private donation.

\section{Ethics Review}

Chesapeake Research Review, LLC (“Chesapeake IRB”).

Note: Chesapeake Research Review, LLC (“Chesapeake IRB”) and Schulman Associates Institutional Review Board, Inc. ("Schulman IRB”) have merged to create Advarra, Inc. (“Advarra IRB”).

\section{Conflicts of Interest}

The authors declare no conflicts of interest regarding the publication of this paper.

\section{References}

[1] Knight, D. (2020) Why Do People Move? New Home Source. https://www.newhomesource.com/learn/author/dknight

[2] Weintraub, E. (2019) Why Do People Sell Their Homes? The Top Reasons Homeowners Make a Move. https://www.thebalance.com/why-home-owners-sell-1799021

[3] Krogh, C.M.E. (2011) Industrial Wind Turbine Development and Loss of Social Justice? Bulletin of Science Technology \& Society, 31, 321-333.

http://bst.sagepub.com/content/31/4/321 https://doi.org/10.1177/0270467611412550

[4] Legislative Assembly of Ontario First Session, 39th Parliament. Report Journal of Debates (Hansard) (Wednesday 15 April 2009) Standing Committee on Green Energy and Green Economy Act, 2009. David Orazietti, Chair. Testimony by Ashbee B., pg. G-516 and the Ripley Group., pg. G-547.

https://www.ola.org/en/legislative-business/committees/general-government/parlia ment-39/transcripts/committee-transcript-2009-apr-15\#P1296_397237 
[5] The Senate, Commonwealth of Australia (2015) Select Committee on Wind Turbines, Interim Report. Wind Farms and Human Health. Para 1.14: pg 3. http://www.aph.gov.au/select_windturbines

[6] Alves-Pereira, M. (2019) Clinical Stages of Vibroacoustic Disease for Occupational Exposures. Invited Talk. University of Waterloo, Ontario. https://livestream.com/itmsstudio/events/8781285/videos/196181579

[7] Krogh, C. (2017) Industrial Wind Turbines Can Harm Humans. Invited Talk. University of Waterloo, Ontario. http://new.livestream.com/itmsstudio/events/2968290

[8] Krogh, C. (2015) Industrial Wind Turbines Can Harm Humans. Invited Talk. Ideacity, Toronto.

http://www.ideacityonline.com/video/carmen-krogh-wind-turbines-can-harm-humans

[9] Facebook (No Date) PDF Copy Available on Request.

[10] Wilson, L. (2009) Farmers Flee as Turbines Trigger Despair. Credited to the Australian. National Wind Watch.

https://www.wind-watch.org/news/2009/08/22/farmers-flee-as-turbines-trigger-des pair

[11] Le Coz, E. and Sherman, L. (2017) In the Shadow of Wind Farms. How the Wind Industry Angers Landowners and Divides Communities in Pursuit of Billions of Dollars in Subsidies and Other Incentives. Gatehouse Media.

http://gatehousenews.com/windfarms/home/?skipintro=true?skipintro=true?skipin tro=true

[12] Hartke, T. (2013) Wind Turbine Meeting Notes. Boone County Zoning Meeting. https://docs.wind-watch.org/Hartke_Submittal-Wind_Farm_Experience_5-28-13.pdf

[13] Jeffery, R.D., Krogh, C. and Horner, B. (2014) (Review) Industrial Wind Turbines and Adverse Health Effects. Canadian Journal of Rural Medicine, 19, 21-26. http://www.ncbi.nlm.nih.gov/pubmed/24398354

[14] CCA (2015) Council of Canadian Academies. Understanding the Evidence. The Expert Panel on Wind Turbine Noise and Human Health.

https://cca-reports.ca/wp-content/uploads/2018/10/windturbinenoisefullreporten.pdf

[15] Jeffery, R.D., Krogh, C. and Horner, B. (2013) (Commentary) Adverse Health Effects of Industrial Wind Turbines. Canadian Family Physician, 59, 473-475. https://www.ncbi.nlm.nih.gov/pmc/articles/PMC3653647

[16] Onakpoya, I.J., O’Sullivan, J., Thompson, M.J. and Heneghana, C.J. (2015) The Effect of Wind Turbine Noise on Sleep and Quality of Life: A Systematic Review and Meta-Analysis of Observational Studies. Environment International, 82, 1-9. http://www.sciencedirect.com/science/article/pii/S0160412015001051 https://doi.org/10.1016/j.envint.2015.04.014

[17] Colby, W., Dobie, R., Leventhall, G., Lipscomb, D.M., McCunney, R.J., Seilo, M.T. and Søndergaard, B. (2009) Wind Turbine Sound and Health Effects: An Expert Panel Review. American Wind Energy Association and Canadian Wind Energy Association.

https://canwea.ca/pdf/talkwind/Wind_Turbine_Sound_and_Health_Effects.pdf

[18] Puzic, S. (2007) Winds of Change. Energy Projects Spark Controversy. The Windsor Star. https://www.pressreader.com/canada/windsor-star/20070908/281483567000248

[19] Bakker, R.H., Pedersen, E., van den Berg, G.P., Stewart, R.E., Lok, W. and Bouma, J. (2012) Impact of Wind Turbine Sound on Annoyance, Self-Reported Sleep Disturbance and Psychological Distress. Science of the Total Environment, 425, 42-51. https://www.rug.nl/research/portal/files/6778722/STOTEN13372.pdf https://doi.org/10.1016/j.scitotenv.2012.03.005 
[20] Niemann, H. and Maschke, C. (2004) WHO LARES Final Report Noise Effects and Morbidity. Interdisciplinary Research Network "Noise and Health". World Health Organization. http://www.euro.who.int/_data/assets/pdf_file/0015/105144/WHO_Lares.pdf

[21] Niemann, H., Bonnefoy, X., Braubach, M., Hecht, K., Maschke, C., Rodrigues, C. and Robbel, N. (2006) Noise-Induced Annoyance and Morbidity Results from the Pan-European LARES Study. Noise Health, 8, 63-79.

http://www.noiseandhealth.org/article.asp?issn=1463-1741; year=2006; volume=8;iss ue $=31$; spage $=63$; epage $=79$; aulast $=$ Niemann https://doi.org/10.4103/1463-1741.33537

[22] McEwen, B.S. (1998) Review Article. Protective and Damaging Effects of Stress Mediators. Seminars in Medicine of the Beth Israel Deaconess Medical Center. The New England Journal of Medicine, 338, 171-179. https://doi.org/10.1056/NEJM199801153380307

[23] Castillo-Montoya, M. (2016) Preparing for Interview Research: The Interview Protocol Refinement Framework University of Connecticut, Storrs, Connecticut, USA. The Qualitative Report, 21, 811-831. https://nsuworks.nova.edu/tqr/vol21/iss5/2

[24] Bloor, M. and Wood, F. (2006) Theoretical Saturation. https://methods.sagepub.com/book/keywords-in-qualitative-methods/n90.xml

[25] Rose, S., Spinks, N. and Canhoto, A.I. (2015) Management Research: Applying the Principles. Routledge, Abingdon-on-Thames, Chapter 6.

[26] Krogh, C.M., McMurtry, R.Y., Dumbrille, A., Hughes, D. and Gillis, L. (2020) Preliminary Results: Exploring Why Some Families Living in Proximity to Wind Turbine Facilities Contemplate Vacating Their Homes-A Community-Based Study. Open Access Library Journal, 7, e6118. https://doi.org/10.4236/oalib.1106118

[27] Green Energy and Green Economy Act, 2009, S.O. 2009, c. 12-Bill 150. Chapter 12 An Act to Enact the Green Energy Act, 2009 and to Build a Green Economy, to Repeal the Energy Conservation Leadership Act, 2006 and the Energy Efficiency Act and to Amend Other Statutes. Assented to May 14, 2009.

http://www.e-laws.gov.on.ca/html/source/statutes/english/2009/elaws_src_s09012_e $\underline{\text { htm }}$ 